Revista Perspectivas Online: Biológicas \& Saúde Novembro/2020, v.10, n.35, p. $12-29$ ISSN: 2236-8868 (Online)

DOI: $10.25242 / / 8868103520202086$

\title{
VIOLÊNCIA OBSTÉTRICA NA VISÃO DE MULHERES NO PARTO E PUERPÉRIO
}

\section{Gittanha Fadja Oliveira Nunes'; Khesia Kelly Cardoso Matos'; Danyella Evans Barros Melo $^{1}$; Lucineide Santos Silva Viana ${ }^{2}$ \& Mariana Mercês Mesquita Espínola ${ }^{3}$}

NUNES, G.F.O.; MATOS, K.K.C.; MELO, D.E.B.; VIANA, L.S.S.; \& ESPÍNOLA, M.M.M. Violência obstétrica na visão de mulheres no parto e puerpério. Perspectivas Online: Biológicas \& Saúde, v.10, n.35, p.12-29, 2020.

\section{RESUMO}

Mulheres grávidas vivenciam situações nem sempre positivas que, por vezes, são marcadas por violações de seus direitos sexuais e reprodutivos. O objetivo deste trabalho foi identificar situações de violência obstétrica (VO) a partir de vivências de mulheres em trabalho de parto, parto e puerpério. $\mathrm{O}$ método utilizado foi à pesquisa descritiva, exploratória de abordagem qualitativa, realizada em maternidades públicas, nas cidades de Petrolina, Pernambuco e Juazeiro, Bahia. Os dados foram coletados através de entrevista semiestruturada e analisados conforme a técnica de Análise de Conteúdo Temático. Foram identificadas situações de VO em que se pode observar problemas organizacionais como reflexo do abuso e desrespeito das instituições, como demora no atendimento, restrição alimentar, problemas de infraestrutura e peregrinação. Além disso, as experiências vivenciadas foram permeadas por entraves na humanização da assistência, em que foi violado o direito das mulheres a uma assistência de qualidade e humanizada. Pode-se perceber também o não reconhecimento da VO pelas parturientes. Conclui-se que é notória a necessidade de estabelecimento de novas práticas nessas instituições com estratégias de reestruturação do atendimento para melhoria na assistência materno-infantil frente ao combate a violência obstétrica.

Palavras-chave: Enfermagem obstétrica; Trabalho de parto; Parto obstétrico; Período pósparto.

\footnotetext{
${ }^{1}$ Instituto de Medicina Integral Professor Fernando Figueira- IMIP- Rua 25, Loteamento Recife, Petrolina, PE, CEP: 56320730, Brasil.

${ }^{2}$ Universidade Federal do Vale do São Francisco-UNIVASF- Rua Santa Cecília, 55, Centro, Petrolina, PE, CEP: 56304-470, Brasil.

${ }^{3}$ Instituto Federal de Pernambuco- IFPE- Rua Bruno Veloso, 257. Boa Viagem, Recife, PE, CEP:51021-280, Brasil.

(*) e-mail: danyella.evans@gmail.com
} 
Online Perspectives Journal: Biological \& Health

November/2020, v.10, n.35, p. $12-29$

ISSN: 2236-8868 (Online)

DOI: $10.25242 / / 8868103520202086$

\title{
OBSTETRIC VIOLENCE IN THE VIEW OF WOMEN IN CHILDBIRTH AND THE PUERPERIUM
}

\section{Gittanha Fadja Oliveira Nunes'; Khesia Kelly Cardoso Matos'; Danyella Evans Barros Melo $^{3}$; Lucineide Santos Silva Viana ${ }^{4}$ Mariana Mercês Mesquita Espínola ${ }^{5}$}

NUNES, G.F.O.; MATOS, K.K.C.; MELO, D.E.B.; VIANA, L.S.S.; \& ESPÍNOLA, M.M.M. Obstetric violence in the view of women in childbirth and the puerperium. Online Perspectives: Biological \& Health, v.10, n.35, p.12-29, 2020.

\begin{abstract}
Pregnant women experience not always positive situations that are sometimes marked by violations of their sexual and reproductive rights. The objective of this study was to identify situations of obstetric violence (VO) from experiences of women in labor, delivery and puerperium. Descriptive, exploratory research of a qualitative approach, carried out in public maternity hospitals, in the cities of Petrolina, Pernambuco and Juazeiro, Bahia. The data were collected through a semi-structured interview and analyzed according to the Thematic Content Analysis technique. VO situations

problems can be observed as a reflection of the abuse and disrespect of institutions, such as delay in attendance, food restriction, infrastructure problems and pilgrimage. In addition, the experiences experienced were permeated by obstacles to the humanization of care, which violated the right of women to quality and humane care. One can also perceive the nonrecognition of $\mathrm{VO}$ by the parturients. It is notorious to establish new practices in these institutions with strategies to restructure care to improve maternal and child care in the fight against obstetric violence.
\end{abstract} were identified in which organizational

Keywords: Obstetric nursing; Labor; Obstetric delivery; Postpartum period.

\footnotetext{
${ }^{1}$ Instituto de Medicina Integral Professor Fernando Figueira- IMIP- Rua 25, Loteamento Recife, Petrolina, PE, CEP: 56320 730, Brasil.

${ }^{2}$ Universidade Federal do Vale do São Francisco-UNIVASF- Rua Santa Cecília, 55, Centro, Petrolina, PE, CEP: 56304-470, Brasil.

${ }^{3}$ Instituto Federal de Pernambuco- IFPE- Rua Bruno Veloso, 257. Boa Viagem, Recife, PE, CEP:51021-280, Brasil.

(*) e-mail: danyella.evans@gmail.com
} 


\section{INTRODUÇÃO}

O ciclo gravídico-puerperal e o nascimento agregam experiências significativas na vida das mulheres e de todo seu círculo familiar. Contudo, essas vivências nem sempre são positivas e, por vezes, são marcadas por violações de seus direitos sexuais e reprodutivos. Não tão raro, sofrem situações de violência nas unidades de saúde que deveriam assisti-las de modo qualificado em suas demandas relacionadas ao trabalho de parto, parto e puerpério (SOUZA, 2019; OLIVEIRA, NOÉLIA, 2015).

Conceitua-se a terminologia "Violência obstétrica" - VO, por atos de violência, de caráter físico, psicológico e/ou verbal, além da realização de práticas inapropriadas durante a assistência obstétrica, por profissionais atuantes nas unidades de atendimento (SAUAIA, SERRA, 2016; CAVALCANTE, 2018). No atual contexto brasileiro, este tipo de violência mostra-se um problema relevante, pois se encontram registros de que uma em cada quatro mulheres atendidas em maternidades públicas brasileiras afirmam ter sofrido algum tipo de VO (Tesser, Knobel, Andrezzo \& Diniz, 2015).

Um dos reflexos dessa violência pode ser evidenciado em práticas de assistência ao parto demasiadamente intervencionistas, o que acaba por retirar da parturiente a sua autonomia durante o processo do nascer (SOUZA, 2019; PEDROSO, LOPEZ, 2017). Esta situação vai desde a escolha da via de parto, o seguimento do trabalho de parto, até a ausência de informações necessárias acerca dos procedimentos e medicações administradas (DINIZ, 2019; ARAÚJO et al 2018). Isso se deve, em grande parte, a hospitalização do parto que anteriormente tinha como essência um acontecimento natural, ocorrido no domicílio, compartilhado em família, mediante cada cultura e valores sociais (Zugaib et al. 2016), (COSTA, 2017) SCARTON et al, 2018)

Ainda de forma corroborativa, observa-se que durante a fase perinatal algumas mulheres são expostas a distintas situações de vulnerabilidade, inclusive física e emocional. Ressalta-se o excessivo número de toques vaginais, a realização de procedimentos sem prévio esclarecimento, a falta de humanização, a infraestrutura precária sem garantir privacidade à paciente, a realização de cesárea sem indicação obstétrica, a peregrinação por serviços de assistência obstétrica e a expressão da relação de "autoridade" profissional/mulher caracterizando-se como atos de violência. Situações mais frequentes quando se trata de mulheres negras e pardas (DINIZ et al, 2016; NASCIMENTO et al 2017).

Embora atos de VO ainda não tenham punição prevista em legislação específica brasileira, ao longo das últimas décadas algumas políticas públicas foram instituídas como forma de assegurar a qualidade da assistência obstétrica. Nesse contexto destaca-se o As Diretrizes Nacionais de Atenção ao Parto Normal, instituídas pelo Ministério da Saúde em 2017 que, dentre outros objetivos, busca estabelecer atendimento baseado em evidências científicas, digno e ético para mãe-família-recém-nascido, além da reestruturação das práticas hospitalares para a atenção ao parto e nascimento.

Nesse contexto, destacam-se ainda a Lei 11.108/2005 que assegura as parturientes o direito à presença de acompanhante durante o trabalho de parto, parto e pós-parto, configurando-se como uma iniciativa importante para a redução de casos de VO, e a Lei $11.634 / 2007$, que dispõe sobre o direito da gestante ao conhecimento e a vinculação à maternidade onde receberá assistência no âmbito do Sistema Único de Saúde (SUS). 
Atualmente, a implementação da lei 1.459/2011, que instituiu a Rede Cegonha, tem tentado assegurar nos diversos serviços que prestam assistência as mulheres no ciclo gravídico puerperal o cumprimento das legislações anteriores. Soma-se a isso a ênfase na redução da mortalidade e melhoria da atenção materno-infantil.

Os movimentos de ativismo de humanização do parto tomam destaque, tanto em âmbito nacional como internacional, no resgate aos direitos sexuais e reprodutivos das mulheres. Sendo o nascimento o evento mais relevante na vida das parturientes, a VO pode transformar o parto em um evento traumático e refletir em uma experiência negativa no indivíduo, na família e na sociedade. Humanizar o parto torna-se, então, imprescindível para tornar este acontecimento "especial" e "inesquecível". Entretanto, para que isso aconteça, é imperioso investir no empoderamento da mulher e utilização de práticas com base científica, tornando, assim, a humanização do parto uma ferramenta de gerenciamento, com a finalidade de diminuir os índices de VO e assim garantir o respeito a mulher (DINIZ, 2019 MARCIANO, R.A. et al, 2015)

Considerando a necessidade de garantir atendimento qualificado e humanizado às mulheres que buscam assistência obstétrica durante o trabalho de parto, parto e puerpério, é imprescindível desvelar as nuances dessa problemática nas maternidades. Para tanto, é necessário dar voz aos profissionais, gestores e, sobretudo às pacientes. A opinião de mulheres que buscam a serviços especializados em ginecologia e obstetrícia tende a ser pertinente devido à possibilidade de denunciar situações que, por vezes, são veladas ou desconhecidas pela sociedade civil e acadêmica.

Assim, o reconhecimento e a discussão das peculiaridades que concebem a VO tornam-se relevantes para a proposição de leis e políticas públicas que indiquem estratégias de enfrentamento e de mudança nos paradigmas assistenciais, a fim de não se perpetuar os atos violentos no cotidiano obstétrico (Jardim \& Modena, 2018).

Diante dessas observações, este estudo objetiva identificar situações de violência obstétrica a partir de vivências de mulheres em trabalho de parto, parto e puerpério que buscam atendimento em maternidades do Vale do São Francisco, nas cidades de Petrolina, Pernambuco e Juazeiro, Bahia, e verificar se as mulheres reconheceram alguma situação de violência em sua assistência.

\section{METODOLOGIA}

Trata-se de um estudo descritivo, exploratório com abordagem qualitativa. A pesquisa foi realizada em duas maternidades públicas na região do Vale do São Francisco, localizadas nos municípios de Juazeiro-BA e Petrolina-PE que atende exclusivamente usuário do Sistema Único de Saúde (SUS). A amostragem foi por conveniência. As puérperas foram contactadas para explanar sobre os objetivos do estudo, nos respectivos leitos, nas enfermarias de puerpério, pela pesquisadora. Participaram do estudo vinte e duas puérperas, com idade igual ou superior a dezoito anos e com boas condições psicológicas e físicas, não importando a via de parto, passado obstétrico e paridade. O número amostral resultou da saturação de respostas das participantes do estudo.

Foi aplicada a técnica de entrevista individual, no período de abril a julho de 2015, nos setores de alojamento conjunto, durante o período de internamento hospitalar. As mulheres entrevistadas foram conduzidas a um local reservado dentro deste setor. Ressalta-se que 
houve o cuidado do momento da entrevista não coincidir com os horários de visitas ou da execução de procedimentos de rotina. Tendo sido todo o conteúdo gravado por meio de aparelho de áudio, com posterior transcrição. A coleta encerrou quando houve saturação dos dados.

O aceite da participação foi documentado por meio da assinatura do Termo de Consentimento Livre e Esclarecido, respeitando os aspectos éticos conforme preconiza a Resolução 466/12 do Conselho Nacional de Saúde. A fim de preservar o anonimato, utilizaram-se, ao longo do texto, a letra (E) seguida de número cardinal de maneira aleatoria para identifcação das participantes. A coleta de dados só teve início após aprovação pelo Comitê de Ética número 0005/111214 CEDEP/UNIVASF.

A análise dos dados foi realizada a partir da técnica de Análise de Conteúdo Temático. Esse método constitui uma técnica que permite tornar replicáveis e válidas deduções sobre dados de um contexto específico, por meio de procedimentos especializados (Minayo, 2007).

\section{RESULTADOS}

Dentre as mulheres investigadas, a média de idade foi 27 anos, sendo que 12 (54,5\%) estavam com menos de 30 anos. A maioria possuia companheiro, 18 (81,8\%), 09 (40,9\%) tinham ensino médio completo, 11 (50\%) intitularam-se como "do lar" e $11(50 \%)$ possuíam renda familiar maior que um salário mínimo. Conforme apresentada na tabela abaixo:

Quanto aos dados obstétricos, apenas 04 eram primíparas, sendo que a maioria teve pelo menos um parto cesáreo (12). Tal resultado não corrobora com a vivência de maternidades púlicas, onde prevalece o parto vaginal (SANTOS, DE JESUS, MENDES, 2019; PINTO et al, 2019).

Após análise do material, foi possível evidenciar diversas situações de violência obstétrica, os mesmos foram agrupados nas seguintes categorias: "A longa espera em uma maca, com fome e humilhada"; os problemas organizacionais no contexto da violência obstétrica; "Ah, na hora de fazer foi bom, porque você agora fica gritando?": os entraves na humanização da assistência; "Apenas maltratada!": o não reconhecimento da violência obstétrica pelas parturientes. Como demostra a tabela a seguir: 
Tabela 1. Categorização dos termos evocados pelas participantes e suas frequências. (N 22)

\begin{tabular}{|c|c|c|}
\hline CATEGORIAS & DEFINIÇÃO & EXEMPLO \\
\hline
\end{tabular}

\begin{tabular}{|c|c|c|c|c|}
\hline $\begin{array}{l}\text { "A longa espera em } \\
\text { uma maca, com } \\
\text { fome e humilhada", }\end{array}$ & $\begin{array}{l}\text { Os Problemas } \\
\text { Organizacionais } \\
\text { No Contexto Da } \\
\text { Violência } \\
\text { Obstétrica }\end{array}$ & $\begin{array}{l}{[\ldots . .] \text { "aí quando passou seis }} \\
\text { horas de relógio em jejum... } \\
\text { ela...a enfermeira disse que } \\
\text { tinha que esperar mais que } \\
\text { tinha urgência...aí eu fiquei lá } \\
\text { esperando e nada.... aí eu } \\
\text { esperei, esperei[...]" }\end{array}$ & 12 & 54,54 \\
\hline $\begin{array}{l}\text { "Ah, na hora de } \\
\text { fazer foi bom, } \\
\text { porque você agora } \\
\text { fica gritando?": }\end{array}$ & $\begin{array}{l}\text { Os entraves na } \\
\text { humanização da } \\
\text { assistência }\end{array}$ & $\begin{array}{l}{[\ldots] \text { "Acho que não, mas se for }} \\
\text { igual eu vi ali, as coitadas } \\
\text { sofrendo e ela sem ligar, se for } \\
\text { desse caso, né? Mas se for de } \\
\text { outro, acho que não } \\
\text {... humilhação que passa, pra } \\
\text { depender que ela tenha a boa } \\
\text { vontade de vir atender você, } \\
\text { falar com você }[. . .] "\end{array}$ & 16 & 72,72 \\
\hline $\begin{array}{l}\text { "Apenas } \\
\text { maltratada!": }\end{array}$ & $\begin{array}{l}\text { O não } \\
\text { reconhecimento } \\
\text { da violência } \\
\text { obstétrica pelas } \\
\text { parturientes }\end{array}$ & $\begin{array}{l}{[. . .] \text { "Eu acho injustiça, não }} \\
\text { tem como não... Nos hospitais } \\
\text { acontecer isso... acontece?.." } \\
{[\ldots]}\end{array}$ & 14 & 63,63 \\
\hline
\end{tabular}

"A Longa Espera Em Uma Maca, Com Fome E Humilhada”: Os Problemas Organizacionais No Contexto Da Violência Obstétrica

De forma geral, os problemas organizacionais inserem-se na violência obstétrica para elencar os pontos primordiais do abuso e desrespeito nas unidades de saúde em contrapartida aos direitos que deveriam ser garantidos (SADLERA et al, 2017). Neste estudo pôde-se relacionar à demora no atendimento, restrição alimentar, problemas de infraestrutura e peregrinação pelas maternidades.

No Brasil, de forma geral, coexiste um entrave no fluxo de atendimento das mulheres no momento anteparto, o que muitas vezes culmina em grande número de parturientes em busca de assistência, peregrinando por duas ou mais unidades de saúde (MENDES et al 2019). Alguns estudos denunciam que o número de maternidades não é proporcional ao crescimento de unidades de referência pré-natal e ao quantitativo de gestantes, o que tende a potencializar o problema (Gottems e cols., 2015; MONTE et al 2018). Entre as mulheres investigadas nesse estudo, a peregrinação durante o trabalho de parto e parto foi relatado por algumas delas: 
[...]Começou por lá, né, no [hospital X] e falaram que eu tinha que vir para [hospital Y], porque o [hospital X] estava muito cheio e estavam ficando só com as cesarianas e iam mandar as normais pra cá. Chegando aqui [...] me falaram [inicialmente] que eu não ia ficar, porque minha vaga era zero e a enfermeira que veio comigo era pra ter entrado, comunicado na recepção, mas ela foi embora, infelizmente fiquei sozinha. [...] (E17)

[...]Olha, geralmente tem sempre um conflito! Porque onde a gente mora, mal tem um hospital que se arrasta e ai quando eles enviam a gente pra cá, é uma burocracia muito grande. Eles não querem atender a gente, eles ficam reclamando que mandam sem num sei o quê, que a gente tem que ir num sei pra onde, ai fica aquela coisa, não é, e quando você vem é porque tá precisando, né! Mas depois que ele humilha bastante ai vai e atende! (risos de desconsolo) [...]. (E19)

O termo "vaga zero" citado pela depoente E17 trata-se de uma expressão regional para justificar a existência da "vaga sempre", enfatizada na Rede Cegonha (2011). Estas garantem disponibilização de um leito obstétrico na assistência ao parto e estabelecem estratégias para vinculação entre pré-natal e parto.

No problema da peregrinação durante o trabalho de parto e parto, também se inserem falhas do Sistema de Regulação de leitos, que muitas vezes tem dificuldade para alocar parturientes de municípios menores para as maternidades de referência, conforme descreve E19 (COSTA, 2018). Essas situações tornam essa experiência em um momento de tensão, com a expressão de sentimentos negativos que as fragiliza, na dúvida de ter ou não assistência de qualidade ao parto e na assistência os cuidados para o seu filho.

Mesmo após peregrinar em busca de assistência, uma vez admitidas, algumas mulheres ainda precisam lidar com a demora no atendimento. Embora muitas delas reivindiquem agilidade em seu atendimento, como forma de assegurar seus direitos de cidadã, outras parecem demonstrar conformidade, sentimento - não tão raro - evidenciado em usuárias do SUS, como demonstra o trecho abaixo:

[...]Demorou bastante tempo, um parto cesário que era pra fazer sete horas, veio fazer bem dizer meia noite, faltando dez minutos. Mas... pelo menos fez, não é! [...] (E4)

[...] a gente chegou aqui $8 h 40$ da manhã [...] só pra simplesmente liberar o exame e dizer o que é que a gente tem [...] Cinco horas da tarde, a gente pediu o exame a moça que fica na recepção, não tinha nem as folhas da impressora pra imprimir os exame, ela ainda foi pegar, botou na mesa da médica [...] recebi 23:15 [só depois disso foi internada] [...]. (E17) 
Durante a coleta de dados foi possível perceber que nessas instituições a espera prolongada esteve relacionada principalmente às limitações de recursos materiais, sobrecarga de trabalho dos profissionais e superlotação. $\mathrm{Na}$ verdade, esta parece ser uma realidade comum entre muitas maternidades públicas do país. O estudo sobre peregrinação de mulheres em busca de atendimento em duas cidades brasileiras evidenciou que a vivência do parto para algumas usuárias pode ser um evento traumático, principalmente para aquelas com baixa renda, mesmo as que a realizaram o pré-natal regularmente, demostrando desigualdades na assistência ao parto e nascimento (MORAES et al 2018). Já para os trabalhadores, trata-se de um desafio no qual é necessário assistir a uma demanda superior à capacidade de atendimento com recursos limitados (RAMOS et al 2018).

Contudo, os problemas estruturais não estão apenas relacionados aos entraves no fluxo de atendimento. Esse contexto também repercute negativamente na qualidade da assistência. Verificam-se em muitos Hospitais materno-infantil deficiências estruturais para acondicionamento de acompanhantes como a ausência de poltronas para os mesmo, falta de privacidade, acomodação em cadeiras de plástico, e no pós-parto ausência de banheiros nos quartos das puérperas no Alojamento Conjunto (CALOU, 2018). Situações como essa perpassam no âmbito da violência obstétrica a partir do momento que passa a ser considerado um atendimento desumano, que repercute na mulher sentimentos de inferioridade (SOUZA et al 2019).

[...] Me colocaram no corredor, nunca senti isso na pele, nunca imaginei que fosse passar por isso, numa maca, não me senti humana! [...] (E22)

[...] Tinha quatro camas na sala e você se ver obrigada a abrir suas pernas e arribar sua roupa ali, na frente de todo mundo para fazer o seu parto! [...] (E19)

$\mathrm{Na}$ tentativa de minimizar parte dos entraves decorrentes da superlotação, alguns autores sugerem como estratégia de curto prazo a implantação de protocolos de atendimento. Essa iniciativa, além de promover uma assistência integral, pode classificar situações de risco e agilizar o atendimento. Dessa forma, é possível priorizar e redirecionar as demandas; potencializar a integração da equipe junto às pacientes/família e melhorar a qualidade da assistência (Silva \& Almeida, 2015; RAMOS et al 2018)

As usuárias investigadas neste estudo demostraram insatisfação com a estrutura física do local, entretanto, chamou-nos a atenção às repetidas queixas relacionadas à fome, seja por longos períodos em "dieta zero" ou por quantidade insuficiente de alimentos. Essas situações de violência obstétrica estão elucidadas abaixo:

[...] eu cheguei aqui na quarta-feira, oito horas da noite e ganhei bebê só hoje, sexta-feira às $2 \mathrm{hl} 15$ da madrugada. Senti muita dor, sem comer nada, só tomando líquido, sem dormir, fraca. Lá (emergência obstétrica) eu estava no corredor, em cima de uma maca, esperando uma vaga que não aparecia! A gente fica lá, jogada, não tem um lugar pra deitar. O espaço é muito ruim. Os alojamentos tudo cheio, não tem maca de jeito nenhum, é uma coisa que 
falam muito: que não tem maca; é horrivel, é triste! [...] (E6)

[...]A gente aqui se queixa muito da alimentação. Porque pra gente que tá amamentando, devia ser um pouquinho mais reforçado, né? Porque dá bastante fome. [...] Eu estava tendo três refeições ao dia desde que eu cheguei aqui [...] (E9)

Queixas relacionadas à restrição alimentar e hídrica também foram evidenciadas em estudos com puérperas em Maceió, Alagoas, o que denota a utilização de práticas assistenciais contrárias às preconizadas pela Rede Cegonha nas "boas práticas de atenção ao parto e ao nascimento", que classifica essa, como prática frequentemente usada de forma inadequada (PINTO et al 2017).

Sabe-se que o trabalho de parto demanda grande gasto energético, sendo que a reposição ineficaz de alimentos e líquidos pode repercutir no bem-estar do binômio (mãe/bebê). Entre os profissionais que adotam essa conduta, prevalece a justificativa pautada no receio às intercorrências e evolução da paciente para um ato cirúrgico e anestésico. Dessa forma, acreditam que mantê-la em dieta zero, pode evitar o risco de bronco-aspiração do conteúdo gástrico (PINTO et al 2017). Outras condutas desumanizantes também foram identificadas nesse estudo (MEDEIROS, 2016).

"Ah, na hora de fazer foi bom, porque você agora fica gritando?": os entraves na humanização da assistência

No presente estudo observou-se que, mesmo em momentos em que as entrevistadas elogiaram a assistência recebida, narraram situações de violência obstétrica evidenciada por fragilidades na humanização. Muitas delas reivindicaram a necessidade de mudança no processo do cuidar.

A humanização pode ser definida como um atendimento que une habilidades teóricas e práticas à abordagem ética, frente a cada indivíduo em suas singularidades (GALLIAN, 2019).Trata-se de uma concepção/ação imprescindível na assistência às mulheres assistidas nas maternidades, com o intuito de assegurar (dentre outras coisas) que o nascimento seja sempre um acontecimento espetacular, envolto por uma assistência digna e de qualidade.

O que se observa na prática é que, entre alguns profissionais, há uma compreensão equivocada sobre a humanização. Nas maternidades estudadas, em conversa informal, percebe-se que para alguns profissionais da equipe multiprofissional, "ser humanizado" relaciona-se à demonstração de atos de carinho, bondade e até mesmo permissividade. Além disso, perpassa características inatas, relacionada meramente a um "estilo" pessoal e que parece ter influência de concepções de poder, masculinidades e gênero. Nesse contexto, a humanização deixa de ser fundamentada em ações de respeito, ética e valorização às subjetividades para ser uma característica, inerente ou não, à personalidade (CAPELANES et al 2020).

As dificuldades enfrentadas pelos profissionais, sejam elas de ordem conceitual, técnica, organizacional, política e/ou pessoal, para promover uma assistência humanizada contribui para a ocorrência da violência obstétrica (INAGAKI et al 2018). Nesse estudo, foram frequentes os relatos de negligência e desrespeito às necessidades das pacientes por 
parte de membros da equipe que as assiste, corroborando para que se sentissem vulneráveis no momento do parto.

[...] eu vi ali, as coitadas sofrendo e elas [membros da equipe] sem ligar [...] Eu acho que é uma TORTURA, a pessoa fica sofrendo e elas nem aí. Isso é uma TORTURA mesmo, porque só a humilhação que passa, para depender que ela tenha a boa vontade de vir atender você, falar com você[...] (E4)

[...]Eu senti dor, e eles não vieram, só porque eu estava praticamente gritando, porque é dor demais e eles deixam você lá sozinha sem dá nenhuma assistência [...]. (E2)

[...] Você é atendida aqui como se fosse um bicho. Não passa aquele afeto, aquele apoio, de você sentir: 'eu estou bem, eu vou sair dessa, não vou morrer!' mas quando você chega, que é mal atendida, primeiramente pensa: 'vou morrer, vou morrer à míngua! [...] (E17)

As queixas atribuídas à sensação de negligência e abandono tendem a se tornar mais frequentes frente ao contexto de superlotação, carência de recursos humanos/ materiais e má valorização do trabalho. Situações, não tão raro, vivenciadas por instituições que atendem ao binômio mãe/bebê na rede pública brasileira. Em estudo multicêntrico realizado com 555 mulheres após assistirem a exposição "sentidos do nascer", que tratava assuntos relacionados a VO, as mesmas relataram que foram impostas a intervenções sem o consentimento, tiveram informações distorcidas sobre procedimento e sentira-se abandonadas. Essas condutas, embora corriqueiras, ocultam a amplitude e gravidade do acontecimento (LANSKY et al 2019)

No discurso da depoente E2, observa-se uma situação já relatada em outros estudos. Foi descrito que pacientes que se expressam com "gritos" tendem a ser classificadas como "escandalosas", "não colaborativas" e que "fazem showzinho". Frequentemente, tais pacientes sofrem ameaças de abandono que expressam o autoritarismo de alguns profissionais de saúde. Essas atitudes não induzem à colaboração, mas submissão, sendo esta uma característica peculiar da violência (BRAGA, 2019).

Os resultados demonstraram que, por vezes, o atendimento aos apelos de dor foram sucedidos por repressão de suas expressões verbais, inclusive com violência verbal.

[...]a gente vem sofrendo, sentindo dor, eles deveriam dar mais atenção, porque tem muitos que mandam calar a boca, parar de zoada, falam isso porque não sabe nem o que a gente tá sentindo! (E9) Uns (profissionais) abrem a boca, ficam vendo as mães gritar, dizem: ah, na hora de fazer foi bom, porque você agora fica gritando? Poxa, a gente sabe que uma relação é diferente de colocar um filho no mundo, é uma dor, é uma coisa que Deus deixou, não é? [...] (E17) 
Uma vez vivenciada essa experiência muitas mulheres optam por silenciar-se com receio de sofrerem novas agressões ou pelo medo e tensão que, muitas vezes, envolve o momento intraparto.

[...]Já fui maltratada, por isso que não gosto de fazer pergunta porque eu não gosto de levar um fora $[\ldots] .(E 12)$

A violência, uma vez consentida, pode trazer danos às mulheres por torná-las cada vez mais vulneráveis a novas violações de seus direitos. Além disso, por fragilizar a relação entre paciente e profissional induz a uma assistência ineficaz. Como consequência, essas mulheres tendem a uma maior suscetibilidade de sofrimento psicoemocional caracterizado por sentimentos negativos como sensação de exclusão e baixa autoestima.

Falar em "falta de humanização" é uma forma mais amena de se deflagrar a violência nos estabelecimentos de saúde. Sendo assim, é necessário que o cuidado seja focado nas necessidades da parturiente e todo seu círculo familiar. No mais, isso mostra a urgência de mudanças na postura profissional que requer investimentos em formação ética e conhecimentos teóricos, para promover uma assistência integral a saúde do binômio mãe/filho. Os profissionais devem ser inseridos na luta do ativismo contra a violência obstétrica e estar dispostos a vivenciar experiências novas na prática, inserindo a mulher nesse contexto em busca do seu empoderamento, no que de fato lhe pertence - o Parto, digno e seguro (PHILIPP, CUNHA, CRUZ, 2018).

\section{“Apenas maltratada!’” o não reconhecimento da violência obstétrica pelas parturientes}

Muitas parturientes ao serem estimuladas a falar sobre violência obstétrica ocorrida em maternidades relatam diversas situações vivenciadas por pessoas do seu ciclo familiar e/ou social. Contudo, mesmo quando referiam à vivência de situações semelhantes durante o seu internamento, negavam ter sofrido VO. Essa negativa perdurou mesmo entre aquelas que julgaram ser maltratadas e sofrerem com os reflexos por longos períodos de sua vida.

Uma das depoentes, mesmo após narrar situação de violência verbal e negligência, quando questionada sobre a possibilidade de ter sofrido violência obstétrica durante sua internação, declarou:

[...]Não! Eu só classificaria o que passei como um maltrato, não só a mim, mas também à vida do meu bebê [...]. (E10)

Muitas experiências foram descritas, como tratamento indigno, desumano, mas não como atos de violência, talvez por possibilidade de desconhecimento do termo. O reconhecimento de VO como ato violento, ainda é escasso na maioria da população. Levandose em conta, principalmente o fato de a vivência do parto ser permeada por um aglomerado de emoções (alegria/dor/amor/medo), faz com que essa mulher se omita, e adquira posição de submissão.

Frente a uma concepção geral e distorcida, nas relações sociais, a violência é vista por muitos apenas como danos físicos. Nesse contexto insere-se à abordagem da violência obstétrica, que é ocasionada por fatores negativos de cunho físico, psicológico e social que 
geram sentimentos de inferioridade na mulher. Por tempos foi negligenciada e despercebida, sendo hoje colocada em destaque para seu reconhecimento e responsabilização dos agressores (CUNHA, 2015).

Ressalta-se, desta forma, a importância da abordagem sobre os direitos referentes ao ciclo gravídico puerperal e educação continuada, que deve ter ênfase maior na assistência prénatal, para que desta forma a mulher esteja apta na tomada de decisões ao que se refere a seu corpo e ao momento do parto, assim como possa denunciar acontecimentos desrespeitosos. As redes sociais tornaram-se importantes ferramentas de apoio e denuncia de mulheres desamparadas. É meio de interação e comunicação entre os usuários que pode abranger todas as classes sociais no Brasil e no mundo (GARCIA JR, CECCON, CRUZ, 2019). Vista isso e a grande repercussão sobre a VO, a Federação Brasileira de Ginecologia e Obsterícia (FEBRASGO) em 2018 publicou recomendações para melhor assistência a mulher durante o trabalho de parto e parto a fim de evitar atos de violência obstétrica, dentre eles o respeito a autonomia e a individualidade da mulher incentivo a presença do acompanhante, a oferta de métodos não farmacológicos para alivio da dor, dieta e ingesta hídrica. No entanto indaga-se sobre a disposição dos profissionais de saúde em instrumentalizar as mulheres e seus familiares quanto a um tipo de violência que pode ser praticada por estes.

A postura profissional omissa e a falta de cobrança ou mesmo uma punição permite que a VO por vezes passe despercebida, contrário ao que ocorre em países como Venezuela e Argentina, com explica Spacov, Silva 2019. Nestes, a violência obstétrica é crime, mediante a gravidade do ato violado coexiste uma multa com valor estimado de 100 a 150 unidades tributárias e até mesmo casos de perda do direito de exercer a profissão (SPACOV, SILVA 2019).

Dessa forma, a negativa ou a imparcialidade sobre VO pode também ser compreendida, por uma das vertentes da psicologia acerca das relações comportamentais, que trabalha sobre o âmbito do realismo X otimismo. Visto que, frente aos princípios básicos da análise do comportamento coexistem determinadas modificações ambientais. Estas podem infuenciar consideravelmente como modificadores para um estímulo discriminatório. A realidade pode ser distorcida, frente à busca por uma realidade mais propícia ou mesmo adaptativa, como se fosse uma válvula de escape para situações negativas, ou como forma de autodefesa. Sendo que isso, não se torna algo completamente ruim, pois funciona como um método de equilíbrio para o indivíduo manter-se bem, frente a circunstâncias inadequadas, mas que pode trazer repercussões psicológicas negativas no futuro. (Benvenut, 2010; DIAS, PACHECO, 2020). Podendo-se esta ser, então, uma das justificativas para que a parturiente mantenha-se em "silêncio", pois frente ao nascimento do um filho o bem-estar deve ser preponderante.

Ademais, o nascimento do bebê é o momento mais esperado, não só pela mãe, mas por todo seu contexto familiar. Observa-se que, não tão raro, são vivenciados acontecimentos que infligem a atenção qualificada e possui tendência a tornar essa experiência traumática (DIAS, 2020).

Alguns autores acreditam que isso está relacionado a assistência prestada a nível hospitalar no processo gestar e parir. $\mathrm{O}$ atendimento que deveria ser focado na humanização, na maioria das vezes não atende as espectativas desta paciente, afetando não somente sua integridade física, mas ocasionando abalo emocional com repercussões futuras, como rejeção do filho, conflitos familiares e conjugais, e comorbidades, como a depressão pós-parto (DIAS, 2020; Peréz, Oliveira \& Lago, 2015; DE ANDRADE et al 2019). O discurso a seguir ratifica: 
[...] Eu não acreditava em depressão pós-parto, mas eu cheguei até no dia que eu estava passando mal, a não querer nem olhar para o meu filho, porque eu achava que a culpa era dele, que eu estava passando por tudo isso por ele. Porque passa pra gente um sentimento de revolta, de muita tristeza. Você saber que vai dar à luz, vai ter um filho e ter que passar por um processo desse, ser mal atendida, maltratada e você ao invés de ouvir apoio, força, você vai ouvir um não! Para mim é revoltante. Eu não merecia, a assistência merece melhorar mais, porque são vidas, e o médico ficou pra salvar vidas $[\ldots](E 17)$

Desta forma, algumas experiências negativas, podem ser denominadas traumáticas, devido ao estresse obstétrico vivenciado, com repercussões psíquicas. Assim, pode repercutir negativamente no relacionamento mãe/bebê, principalmente a dificuldade de amamentar, em que são impedidas de amamentar na primeira hora de vida, na vida conjugal e reprodutiva para estas mulheres, como o medo de uma gestação futura, assim como no âmbito familiar (SANTIAGO, SOUZA, NASCIMENTO, 2017; MEDEIROS, MARTINS, CAMBOIM, 2016).

\section{CONCLUSÕES}

Frente ao relato das puérperas entrevistadas foi possível identificar a violência obstétrica como uma prática comum nas maternidades apresentadas neste estudo. As queixas mais frequentes foram relacionadas à peregrinação pelas maternidades, demora no atendimento, condições precárias de infraestrutura, restrição alimentar, falta de humanização pelos profissionais, violência verbal, dificuldades para reconhecer atos de $\mathrm{VO}$ e reflexos da violência, como experiência traumática na vida das mulheres e todo seu contexto familiar.

Além do mais, para alguns profissionais persitem a ideia equivocada sobre a humanização do parto na perspectivas das participantes. E mesmo após o ato de VO, a maioria opta por silenciar-se com receio de sofrerem novas agressões, podendo até negar ocorrido, como citado no presente estudo.

Ressalta-se ainda que a violência obstétrica é um termo pouco conhecido por muitas classes, fazendo-se necessário atualizações frente a essa temática, assim como instrumentalizar a população e profissionais de saúde a não se omitirem perante esses casos, frente ao fortalecimento de combate a esse tipo de violência.

Contudo, sugere-se o estabelecimento/estruturação de novas práticas nessas instituições, com estratégias para melhoria nos fatores organizacionais determinantes à prestação de assistência à saúde qualificada, como infra-estrutura e distribuição de recursos humanos, de modo a otimizar o serviço e a assistência ofertada à paciente, promovendo a sensibilização dos profissionais para um atendimento mais humanizado, com foco na melhoria da qualidade do cuidado prestado, no cumprimento dos direitos estabelecidos por lei para as mulheres, sobretudo no ciclo gravídico-puerperal. 
Ademais, também fica evidenciada a necessidade novos debates sobre a temática, de modo a discutir estratégias que modifiquem práticas assistenciais que levam as situações de violência obstérica e a desqualificação do cuidado em saúde ofertado.

\section{REFERÊNCIAS}

ARAÚJO, L.A.M.; RIBEIRO, J.F.; NASCIMENTO, J.J.; MOTA, T.C.; OLIVEIRA, E.M.; FIGUEIREDO, T.S.; LAVOR, T.B.S.L.; \& SILVA, S.C.E. Escolha de via de parto em uma maternidade de referência em Teresina-PI. Revista Eletrônica Acervo Saúde, v. 11, n. 3, p. e196, 29 dez. 2018. Disponível em: < https://www.acervomais.com.br/index.php/saude/article/view/196>. Acesso em: 03 jul.2020.

BENVENUTI, M.F.L. Contato com a realidade, crenças, ilusões e superstições: Possibilidades do analista do comportamento. Revista Perspectivas, 1(1):34-43. 2010. Disponível em: < http://pepsic.bvsalud.org/pdf/pac/v1n1/v1n1a06.pdf>. Acesso em 15 mai. 2020.

BRAGA, E. B.; LEITÃO, E.K.F.; DE OLIVEIRA, I.B.; BONFIM, L. O.; DE OLIVEIRA, M.G.; \& DO BOMFIM, A.T. Violência obstétrica durante o trabalho de parto. Anais eletrônico cic, v. 17, n. 17, 2019. Disponível em: $<$ http://fasb.edu.br/revista/index.php/cic/article/view/430>. Acesso em: 08 jul. 2020.

BRASIL. Ministério da Saúde. Secretaria de Ciência, Tecnologia e Insumos Estratégicos. Diretrizes nacionais de assistência ao parto normal: versão resumida. 2017. Disponível em: http://bvsms.saude.gov.br/bvs/publicacoes/diretrizes_nacionais_assistencia_parto_normal.pdf. Acesso em: 14 jun. 2019.

CALOU, C.G.P. Maternidade segura: estrutura física e organizacional de instituições habilitadas pela Rede Cegonha. 2018. Disponível em: $<$ http://repositorio.ufc.br/handle/riufc/34909>. Acesso em: 07 jul. 2020.

CAPELANES, B.C.S.; DA SILVA SANTOS, M.P.; REZENDE, K.T.A.; \& CHIRELLI, M.Q. Cuidado humanizado às gestantes, parturientes e puérperas: análise temática da concepção dos profissionais de saúde. New Trends in Qualitative Research, v. 3, p. 648-663, 2020. Disponível em: < https://publi.ludomedia.org/index.php/ntqr/article/view/192>. Acesso em: 30 set. 2020 .

CAVALCANTE, A.C.M; SOUZA, F.M.A.; ALBURQUERQUE, C.M.; COUTO, C.S.; ROLIM, K.M.C.; CHAVES, J.; SANTOS, Z.M.S.A.; \& FROTA, M.A. Violência obstétrica: desvelando suas consequências. CIAIQ2018, v. 2, 2018. Disponível em: $<$ https://proceedings.ciaiq.org/index.php/ciaiq2018/article/view/1852>. Acesso em: 05 jul. 2020.

COSTA, M.N.; DA SILVA, J.D.F.O.; SILVA, L.D.A.; GALDINO, C.V.; \& BRÁS, M.R. Parto: direito de escolha da mulher. Revista Saber Digital, v. 8, n. 01, p. 146-163, 2017.) Disponível em: <http://revistas.faa.edu.br/index.php/SaberDigital/article/view/395>. Acesso em: 05 jul. 2020.

COSTA, R.L.M.. Percepções de mulheres que vivenciaram a peregrinação anteparto na rede pública hospitalar. Revista Baiana de Enfermagem, v. 32, 2018. Disponível em: $<$ https://portalseer.ufba.br/index.php/enfermagem/article/view/26103>. Acesso em: 04 jul. 2020 . 
CUNHA, C.C.A. Violência obstétrica: uma análise sob o prisma dos direitos fundamentais (Trabalho de Conclusão de Curso). Universidade de Brasília Faculdade de Direito, Brasília, DF, Brasil. 2015. Disponível em: $<$ http://bdm.unb.br/bitstream/10483/10818/1/2015_CamilaCarvalhoAlbuquerqueCunha.pdf $>$. Acesso em: 14 fev. 2020.

DE ANDRADE, V.B.; DA PAZ SANTOS, C.; DOS SANTOS, S.; \& DA SILVA, W.M. Efeitos da violência obstetrica causados ás gestantes no parto e pós-parto: e a humanização da assistência de enfermagem. Gep News, v. 2, n. 2, p. 69-74, 2019. Disponível em: $<$ https://www.seer.ufal.br/index.php/gepnews/article/view/7881 $>$. Acesso em: 01 de out. 2020.

DINIZ, C.S. A vivência do parto e a violência obstétrica na visão das mulheres: um estudo de revisão bibliográfica. Monografia (Graduação em Saúde Coletiva) - Instituto de Estudos em Saúde Coletiva, Universidade Federal do Rio de Janeiro, Rio de Janeiro, 2019. Disponível em: <https://pantheon.ufrj.br/handle/11422/8825>. Acesso em: 04 de jul. 2020.

DIAS, S. L.; \& PACHECO, A.O. Marcas do parto: As consequências psicológicas da violência obstétrica. Revista Arquivos Científicos (IMMES), v. 3, n. 1, p. 04-13, 2020. Disponível em: <http://arqcientificosimmes.emnuvens.com.br/abi/article/view/232>. Acesso em: 07 jul. 2020

DINIZ, C.S.G.; BATISTA, L.E.; KALCKMANN, S.; SCHLITHZ, A.O.; QUEIROZ, M.R.; \& CARVALHO, P.C.D.A. Desigualdades sociodemográficas e na assistência à maternidade entre puérperas no Sudeste do Brasil segundo cor da pele: dados do inquérito nacional Nascer no Brasil (2011-2012). Saúde e Sociedade. v. 25. 2016. Disponível em: $<$ https://www.scielosp.org/article/sausoc/2016.v25n3/561-572>. Acesso em: 01 mar. 2020.

FEBRASGO. Federação Brasileira de Ginecologia e Obstetrícia. Recomendações da Febrasgo para temas controversos. Disponível em: $<$ https://www.febrasgo.org.br/en/component/k2/item/694-recomendacoes-febrasgo-paratemas-controversos>. Acesso em: 05 jul. 2020.

GAllian, D.M.C. Humanização em saúde e reforma. Physis: Revista de Saúde Coletiva, v. 29, n. 4, p. e290408, 2019.. Disponível em: $<$ https://www.scielosp.org/pdf/physis/2019.v29n4/e290408>. Acesso em: 10 jul. 2020.

GARCIA JR, C.A.S.; CECCON, R.F.; \& CRUZ, D.V. Violência obstétrica: estratégias de produção do cuidado em ambientes virtuais no brasil. Rizoma: Experiências interdisciplinares em ciências humanas e sociais aplicadas, v. 4, n. 1, 2019. Disponível em: <http://revistaadmmade.estacio.br/index.php/rizoma/article/view/6657>. Acesso em: 09 jul. 2020.

GOTTEMS, L.B.D. et al. Acesso à rede de atenção a gestação, parto e nascimento na perspectiva das usuárias. Revista Eletrônica Gestão \& Saúde, 6(1): 95-15. 2015. Disponível em: < http://periodicos.unb.br/index.php/rgs/article/view/2531/2258>. Acesso em: 09 jul. 2020 .

INAGAKI, A.D.D.M.; LOPES, R.J.P.L.; CARDOSO, N.P.; FEITOSA, L.M.; ABUD, A.C. F.; \& RIBEIRO, C.J.N. Fatores associados à humanização da assistência em uma maternidade pública. Revista de enfermagem UFPE on-line., Recife, v. 12, n.7, p.1879-86, jul., 2018. Disponível em: $<$ https://repositorio.ifs.edu.br/biblioteca/handle/123456789/721 >. Acesso em: 09 jul. 2020.

JARDIM, D.M.B.; MODENA, C.M. (2018). La violencia obstétrica en el cotidiano asistencial y sus características. Revista Latino-Americana de Enfermagem, v. 26, 2018. 
Disponível

em: $<$

https://www.scielo.br/scielo.php?pid=S0104$11692018000100613 \&$ script $=$ sci_arttext\&tlng=es >. Acesso em: 04 jul. 2020.

LANSKY, S. et al. Violência obstétrica: influência da Exposição Sentidos do Nascer na vivência das gestantes. Ciência \& Saúde Coletiva, v. 24, p. 2811-2824, 2019.Disponível em: $<$ https://www.scielosp.org/article/csc/2019.v24n8/2811-2824/>. Acesso em: 09 jul. 2020.

Lei n. 11.108, de 7 de abril de 2005. Altera a Lei n. 8.080, de 19 de setembro de 1990, para garantir às parturientes o direito à presença de acompanhante durante o trabalho de parto, parto e pós-parto imediato, no âmbito do Sistema Único de Saúde - SUS. Disponível em http://www.planalto.gov.br/ccivil_03/_Ato2004-2006/2005/Lei/L11108.htm

Lei n. 11.634, de 27 de dezembro de 2007. Dispõe sobre o direito da gestante ao conhecimento e a vinculação à maternidade onde receberá assistência no âmbito do Sistema Único de Saúde. Disponível em http://www.planalto.gov.br/ccivil_03/_Ato20072010/2007/Lei/L11634.htm

MARCIANO, R.; PIMENTEL, P.; MAGALHÃES, C.; \& ESPARRACHIARI, L. Conhecimento de gestantes sobre a humanização do parto: uma intervenção educativa. Biológicas \& Saúde, v. 5, n. 18, 24 nov. 2015. Disponível em: $<$ https://ojs3.perspectivasonline.com.br/biologicas_e_saude/article/view/769/617>. Acesso em: 21 jul. 2020.

MEDEIROS, N.C.M; MARTINS, E.N.X.; \& CAMBOIM, F.E.F. Violência obstétrica: percepções acerca do parto normal. 2016. Disponível em: < http://temasemsaude.com/wpcontent/uploads/2016/09/16331.pdf > . Acesso em 05 jul. 2020.

MENDES, R.B. et al. Características maternas e da assistência pré-natal associadas à peregrinação no anteparto. Revista de Saúde Pública, v. 53, p. s1518-8787.2019053001087, 2019. Disponível em: https://www.scielosp.org/article/rsp/2019.v53/s15188787.2019053001087/pt/. Acesso em: 04 jul. 2020.

MINAYO, M.C.S. O desafio do conhecimento: Pesquisa qualitativa em Saúde. 10a ed.. 2007. São Paulo: Hucitec.

MONTE, A.S. et al. Near miss materno: fatores influenciadores e direcionamentos para redução da morbidade e mortalidade materna. Revista Rene (Online), p. e3182-e3182, 2018. Disponível em: $<$ https://www.researchgate.net/profile/Monica_Oria/publication/324020065_Near_miss_mate rnal_influencing_factors_and_guidelines_for_reducing_maternal_morbidity_and_mortality/li $\mathrm{nks} / 5 \mathrm{ac} 22 \mathrm{ee} 6 \mathrm{a} 6 \mathrm{fdcccda} 65 \mathrm{e} 9 \mathrm{e} 33 /$ Near-miss-maternal-influencing-factors-and-guidelines-forreducing-maternal-morbidity-and-mortality.pdf >. Acesso em: 08 jul. 2020.

MORAES, L.M.V. de et al. Fatores associados à peregrinação para o parto em São Luís (Maranhão) e Ribeirão Preto (São Paulo), Brasil: uma contribuição da coorte BRISA. Cadernos de Saúde Pública, v. 34, p. e00151217, 2018. Disponível em: $<$ https://www.scielosp.org/article/csp/2018.v34n11/e00151217/>. Acesso em: 09 jul. 2020.

NASCIMENTO, L.C. et al. Relato de puérperas acerca da Violência Obstétrica nos serviços públicos. Revista de Enfermagem UFPE on-line, Recife, v. 11, supl. 5, p. 2014- 2023, 2017. Disponível em: $\quad<$ https://periodicos.ufpe.br/revistas/revistaenfermagem/ article/download/23355/18974>. Acesso em: 15 nov. 2019.

OLIVEIRA, T.C.; \& NOÉLIA, N.N.S.C. Direito ao parto humanizado: experiência e legalidade na visão das puérperas. Biológicas \& Saúde, v. 5, n. 18, 24 nov. 2015. Disponível em: $\quad<$ https://ojs3.perspectivasonline.com.br/biologicas_e_saude/article/view/775/623>. Acesso em: 21 jul. 2020. 
PEDROSO, C.N.L.S; \& LÓPEZ, L.C. À margem da humanização?: experiências de parto de usuárias de uma maternidade pública de Porto Alegre, RS. Physis: Revista de Saúde Coletiva, v. 27, p. 1163-1184, 2017. Disponível em: https $<$ https://www.scielosp.org/article/physis/2017.v27n4/1163-1184/pt/>. Acesso em: 15 nov. 2019.

PERÉZ, B.A.G.; OLIVEIRA, E.V.; \& LAGO, M.S. Percepções de puérperas vítimas de violência institucional durante o trabalho de parto e parto. Revista Enfermagem Contemporânea, 4(1):66-77. 2015. Disponível em: $<$ http://pepsic.bvsalud.org/scielo.php?script=sci_arttext\&pid=S2177-35482010000100006.>. Acesso em: 06 mai. 2020.

PHILIPP, R.R.; CUNHA, T.R.A.; \& CRUZ, Z.V.C.V. Breve discussão sobre a violência obstétrica contra as mulheres:"na hora de abrir as pernas ninguém reclama". Revista NUPEM, v. 10, n. 21, p. 110-123, 2018. Disponível em: $<$ http://revistanupem.unespar.edu.br/index.php/nupem/article/view/436>. Acesso em: 06 jul. 2020.

PINTO, J.N.S et al. Incidência de parto cesárea em uma maternidade no município de Porto Velho - RO em 2017. Revista Eletrônica Acervo Saúde, n. 33, p. e1241, 4 set. 2019. Disponível em: $<$ https://www.acervomais.com.br/index.php/saude/article/view/1241> .Acesso em: 05 jul. 2020.

PINTO, L.M.T.R et al. Food management during childbirth under woman's perception/O manejo alimentar durante o parto sob a percepcao da mulher/Manejo de alimentos durante el parto bajo la percepcion de la mujer. Revita de Enfermagem UERJ. v.25, n 1. 2017. Disponível em: $<$ https://go.gale.com/ps/anonymous? $\mathrm{id}=\mathrm{GALE} \% 7 \mathrm{CA} 568569226 \&$ sid=googleScholar\&v=2.1 \&it $=\mathrm{r} \&$ linkaccess $=$ abs\&issn $=01043552 \& \mathrm{p}=\mathrm{AONE \& sw}=\mathrm{w}>$. Acesso em: 16 mar. 2020.

Portaria n. 1459, de 24 de Junho de 2011. Institui, no âmbito do Sistema Único de Saúde SUS - a Rede Cegonha. Brasília-DF. Acesso em 14 de março de 2020. Disponível em: $<$ http://bvsms.saude.gov.br/bvs/saudelegis/gm/2011/prt1459_24_06_2011.html >

RAMOS, L. et al. Acolhimento com classificação de risco: percepção dos enfermeiros em uma maternidade pública. Revista Interdisciplinar, v. 11, n. 3, p. 103-113, 2018. Disponível em: $<$ https://dialnet.unirioja.es/servlet/articulo?codigo=6763760>. Acesso em: 05 jul. 2020.

SADLERA, M. et al. Para além do desrespeito e do abuso: as dimensões estruturais da violência obstétrica. Violência: uma barreira para a saúde e os direitos sexuais e reprodutivos, p. 64, 2017.. Disponível em: <http://www.srhm.org/wp-content/uploads/2018/04/2017-RHMin-Portuguese.pdf\#page $=64>$. Acesso em: 06 jul. 2020.

SANTIAGO, D.C.; SOUZA, W.K.S.; \& NASCIMENTO, R.F. Violência Obstétrica: uma análise das consequências. Revista Científica da FASETE, v. 148, 2017. Disponível em: $<$ https://www.unirios.edu.br/revistarios/media/revistas/2017/13/violencia_obstetrica_uma_an alise_das_consequencias.pdf $>$. Acesso em: 01 jul. 2020.

SPACOV, L.V.; \& DA SILVA, D.S.R. Violência obstétrica: um olhar jurídico desta problemática no brasil. 2019.2 Disponível em: $<$ http://www.mpsp.mp.br/portal/page/portal/documentacao_e_divulgacao/doc_biblioteca/bibli _servicos_produtos/bibli_boletim/bibli_bol_2006/Derecho-y-Cambio_n.55.23.pdf $>$. Acesso em: 01 jul. 2020. 
SAUAIA, A.; \& SERRA, M.C. Uma dor além do parto: Violência em foco. Revista .Direitos Humanos e Efetividade, v. 2, n.1, p. 128-147. Brasília: 2016. Disponível em: $<$ http://indexlaw.org/index.php/revistadhe/article/view/1076/1072>. Acesso em: 19 out. 2019.

SANTOS, J.M.J.; DE JESUS, L.L.; \& MENDES, R.B. Prevalência dos tipos de parto e de suas características na parturição em um município do Nordeste brasileiro. In: Congresso Nacional de Enfermagem-CONENF. 2019. Disponível em: $<$ https://eventos.set.edu.br/index.php/conenf/article/view/9336/0 >. Acesso em: 05 jul. 2020.

SCARTON, J.; RESSEL, L.B.; SIQUEIRA, H.C.H.; RANGEL, R.F.; TOLFO, F.; \& WEYKAMP, J.M. Pratica de atenção ao parto normal: a experiência de primíparas. Revista Online de Pesquisa, 2018. v.10. $\mathrm{n}^{\mathrm{o}} 1$. 8p. Disponível em: < http://www.seer.unirio.br/index.php/cuidadofundamental/article/view/5918/pdf > . Acesso em: 30 ago. 2019.

SILVA, A.L.S.; \& ALMEIDA, L.C.G. Vivências de mulheres frente a peregrinação para o parto. Revista Eletrônica Atualiza Saúde, 2015. 2(2): 07-19. Disponível em: $<$ http://atualizarevista.com.br/wp-content/uploads/2015/07/Viv\%C3\%AAncia-de-mulheresfrente- $\% \mathrm{C} 3 \% \mathrm{~A} 0$-peregrina $\% \mathrm{C} 3 \% \mathrm{~A} 7 \% \mathrm{C} 3 \% \mathrm{~A} 30-$ para-o-parto-v.2-n.2.pdf $>$. Acesso em: 14 jan. 2020.

SOUZA, D.S.; \& OLIVEIRA, T.C.F.D. Na hora de fazer não gritou: a violência obstétrica nas mulheres parturientes. SEMOC-Semana de Mobilização Científica, 2019. Disponível em: $<$ http://ri.ucsal.br:8080/jspui/handle/prefix/1261 >. Acesso em: 01 jul. 2020.

TESSER, C.D.; KNOBEL, R.; ANDREZZO, H.F.S.; \& DINIZ, S.G. Violência obstétrica e prevenção quaternária: o que é e o que fazer. Revista Brasileira Medicina de Família e Comunidade, 2015. 10(35):1-12. Disponível em $<$ https://www.rbmfc.org.br/rbmfc/article/view/1013>. Acesso em: 14 de mar. 2020.

ZUGAIB, Marcelo et al. Obstetrícia. $3^{\circ}$ ed, cap. 03, 69, 71. Barueri, SP: Manole, 2016. 